\title{
Anesthetic course and complications that were encountered during endoscopic thyroidectomy -A case report-
}

\author{
Su-Nam Lee, Ji- Heui Lee, Eun-Ju Lee, Ji-Yeon Lee, Jong-Il Kim, and You-Bin Son \\ Department of Anesthesiology and Pain Medicine, Korea Cancer Center Hospital, Seoul, Korea
}

Endoscopic thyroidectomy is gaining popularity, but it can increase the risk of certain complications. Carbon dioxide insufflation in the neck may cause adverse effects on hemodynamic and ventilatory aspects. We report the anesthetic course and complications that were encountered during endoscopic thyroidectomy. Although the surgery was successful, the patient developed signs of hypercarbia, subcutaneous emphysema and pneumothorax. (Korean J Anesthesiol 2012; 63: 363-367)

Key Words: Endoscopic thyroidectomy, Hypercarbia, Peumothorax, Subcutaneous emphysema.

Endoscopic thyroidectomy, originally introduced during the mid-1990s, has recently gained popularity among various health care facilities for its obvious cosmetic advantages. But with its increased popularity comes increased risks of adverse effects [1]. Most events are respiratory complications resulting from the body's absorption of carbon dioxide $\left(\mathrm{CO}_{2}\right)$ used during the surgery: the reported side effects include hypercapnia, subcutaneous emphysema, mediastinal emphysema, and pulmonary embolism. Pneumothorax, however, has not been reported yet. We experienced pneumothorax during an endoscopic thyroidectomy and hereby present the case with a review of the literature.

\section{Case Report}

A 22-year-old woman, weighing $51 \mathrm{~kg}$, visited this hospital, complaining of a thyroid nodule and septal deviation. It was decided that an endoscopic thyroidectomy and septoplasty was to be performed on her. Our review of medical history and a preoperative examination showed no particular conditions to consider. Prior to the surgery, patient's condition was monitored via ECG and noninvasive blood pressure monitoring; Oxygen saturation and end-tidal $\mathrm{CO}_{2}$ pressure $\left(\mathrm{PetCO}_{2}\right)$ were measured. After the IV infusion of thiopental sodium $(250 \mathrm{mg})$ and vecuronium $(6 \mathrm{mg})$, endotracheal intubation was performed with no particular problems. General anesthesia was induced and maintained with $\mathrm{O}_{2} 2 \mathrm{~L} / \mathrm{min}, \mathrm{N}_{2} \mathrm{O} 2 \mathrm{~L} / \mathrm{min}$, and sevoflurane. Mechanical ventilation was provided with a tidal volume of 500 $\mathrm{ml}$, a respiratory rate of $10 / \mathrm{min}$, and a peak inspiratory pressure (PIP) of $18 \mathrm{cmH}_{2} \mathrm{O}$. Oxygen saturation after the induction of anesthesia was $99 \%$; PetCO $_{2}$ was $34-36 \mathrm{mmHg}$.

A small incision was made in the patient's right armpit area,

Received: August 19, 2011. Revised: October 12, 2011. Accepted: October 23, 2011.

Corresponding author: Su-Nam Lee, M.D., Department of Anesthesiology and Pain Medicine, Korea Cancer Center Hospital, 75, Nowon-gil (215-4 Gongneung-dong), Nowon-gu, Seoul 139-706, Korea. Tel: 82-2-970-1259, Fax: 82-2-970-2161, E-mail: sunamlee@naver.com (c) This is an open-access article distributed under the terms of the Creative Commons Attribution Non-Commercial License (http:// creativecommons.org/licenses/by-nc/3.0/), which permits unrestricted non-commercial use, distribution, and reproduction in any medium, provided the original work is properly cited. 
through which two trocars, $10 \mathrm{~mm}$ and $12 \mathrm{~mm}$ in diameter, were each inserted; another $12 \mathrm{~mm}$ trocar was infiltrated through an incision made in the area above right nipple; all trocars were inserted beneath the pectoral muscles. $\mathrm{CO}_{2}$ was continuously administered under the platysma muscle at $8 \mathrm{mmHg}$ to create an air pocket and to allow the surgery to proceed.

About 30 minutes after the injection of $\mathrm{CO}_{2}$, PetCO $\mathrm{CO}_{2}$ and PIP started to show a gradual increase; after 40 minutes, the PetCO and PIP reached $41 \mathrm{mmHg}$ and $22 \mathrm{cmH}_{2} \mathrm{O}$, respectively. Thus, the respiration rate was increased to $14 / \mathrm{min}$ while maintaining the tidal volume. The PetCO ${ }_{2}$ and PIP continued to increase in small increments until approximately 50 minutes after the $\mathrm{CO}_{2}$ injection, at which point the $\mathrm{PetCO}_{2}$ soared abruptly to 49 $\mathrm{mmHg}$ and the PIP to $35 \mathrm{cmH}_{2} \mathrm{O}$, while the oxygen saturation dropped to $94 \%$. When this occurred, the patient's vitals were a blood pressure of $118 / 70 \mathrm{mmHg}$ and a heart rate of 100 beats/min. Mechanical ventilation was immediately shifted to manual ventilation; $100 \%$ oxygen was administered; both of lungs were examined with a stethoscope because we suspected pneumothorax after excluding the possibilities of respiratory obstruction resulting from one lung ventilation or secretion, or the possibilities of a bent tube or interruption in the respiratory cycle. Respiratory sounds from left lung were normal, but the sounds from right lung were diminished. During the stethoscopy, crepitant rales were heard as well, and thus the patient's condition was checked. Subcutaneous emphysema was found in the neck, shoulders, arms, and thoracic wall. Thus, an arterial blood gas analysis was done, which revealed a $\mathrm{pH}$ of 7.24, a $\mathrm{PaCO}_{2}$ of $54.6 \mathrm{mmHg}$, a $\mathrm{PaO}_{2}$ of $162.5 \mathrm{mmHg}$, a $\mathrm{SaO}_{2}$ at $99 \%$, and a base excess of $-3.6 \mathrm{mEq} / \mathrm{L}-$ all of which indicated

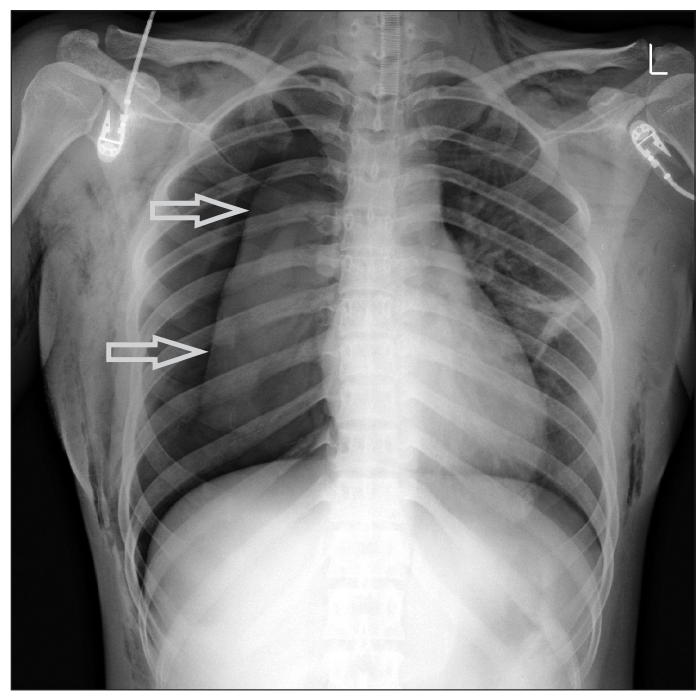

Fig. 1. Intra-operative chest AP shows right pneumothorax and subcutaneous emphysema. respiratory acidosis. Chest X-rays showed pneumothorax in right lung (Fig. 1). A chest tube was inserted into right lung; multiple manual ventilations were carried out to achieve a full expansion of the lung. The anesthesia was maintained with $\mathrm{O}_{2}$ air-sevoflurane. At this point, $\mathrm{PetCO}_{2}$ decreased to $37 \mathrm{mmHg}$, and PIP to $19 \mathrm{cmH}_{2} \mathrm{O}$. After making sure the patient's respiratory condition was stabilized, the operation was resumed. About 10 minutes into the surgery, PetCO ${ }_{2}$ increased gradually to 46 $\mathrm{mmHg}$, whereas PIP remained the same. At this point, another arterial blood gas analysis was done, which showed a $\mathrm{pH}$ of 7.27, a $\mathrm{PaCO}_{2}$ of $51.6 \mathrm{mmHg}$, a $\mathrm{PaO}_{2}$ of $317.8 \mathrm{mmHg}$, a $\mathrm{SaO}_{2}$ at $99 \%$, and a base excess of $-3.2 \mathrm{mEq} / \mathrm{L}$. Blood pressure was 120/80 mmHg; heart rate was 98 beats $/ \mathrm{min}$. We assumed that the hypercapnia would probably continue due to the increased absorption of $\mathrm{CO}_{2}$ because of the subcutaneous emphysema. Thus, we consulted with the surgeon and decided to continue only with the endoscopic thyroidectomy and to delay the septoplasty.

The surgery was finished two hours and 20 minutes after the insertion of the chest tube. Extubation took place in the operating room after ensuring a full recovery of the patient's respiration and consciousness. The patient did not exhibit any difficulty breathing.

Upon arrival at the recovery area, oxygen $(5 \mathrm{~L})$ was delivered via a facemask. An arterial blood gas analysis, done 15 minutes after the administration of oxygen, revealed a $\mathrm{pH}$ of 7.34 , a $\mathrm{PaCO}_{2}$ of $33.5 \mathrm{mmHg}$, a $\mathrm{PaO}_{2}$ of $190.6 \mathrm{mmHg}$, a $\mathrm{SaO}_{2}$ at $99 \%$, and a base excess of $-6.0 \mathrm{mEq} / \mathrm{L}$. The chest X-rays showed only mild subcutaneous emphysema (Fig. 2). A CT scan two days postoperatively revealed no adverse events such as lung bulla.

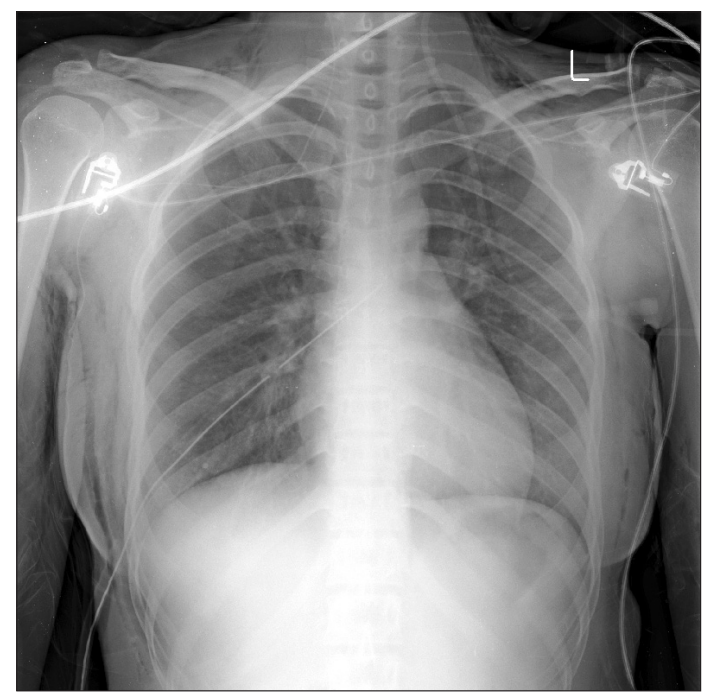

Fig. 2. Chest radiograph taken at PACU shows relieved pneumothorax. 
The patient was discharged on the fifth day after the operation without exhibiting any particular complications.

\section{Discussion}

An ideal gas for gas injection during a laparoscopy should have minimal absorption into the abdominal cavity as well as minimal physiological effects; be quickly discharged from the body; and have no inflammability yet high solubility in blood [2]. $\mathrm{CO}_{2}$ matches those parameters closely and is frequently used in laparoscopic or endoscopic procedures. In the case of pneumoperitoneum, $\mathrm{CO}_{2}$ can be eliminated quickly and helps minimize the patient's postoperative discomfort. Its many advantages notwithstanding, $\mathrm{CO}_{2}$, when absorbed into the blood, can cause hypercapnia, subcutaneous emphysema, pneumothorax, and embolism [3,4].

During a laparoscopic abdominal surgery, the absorption of $\mathrm{CO}_{2}$ in the body continues to increase for the first 20 minutes until it levels out. On the contrary, during a laparoscopic procedure done in sites other than the abdominal/pelvic cavity, the absorption of $\mathrm{CO}_{2}$ continues to increase over time, reportedly resulting in hypercapnia and subcutaneous emphysema that are worse than that of those occurring during laparoscopic abdominal surgeries. Mechanisms behind such difference are two-fold: (a) with an abdominal gas injection pressure of 10-12 mmHg or above, the blood flow into the capillaries decreases, resulting in a decrease in $\mathrm{CO}_{2}$ absorption in the abdominal/pelvic cavity; and (b) during gas injection into a cavity other than the abdominal/pelvic cavity, the continued tissue dissection increases the area that comes in contact with the gas $[5,6]$. In order to decrease hypercarbia, the respiratory minute ventilation must be increased and the gas injection pressure decreased. Generally speaking, the $\mathrm{PetCO}_{2}$ can be normalized during a laparoscopy by increasing the respiratory minute ventilation by $35-60 \%[3,5]$.

Hemodynamic and respiratory adverse events, resulting from hypercapnea during a laparoscopy, are influenced by the pressure at which $\mathrm{CO}_{2}$ is injected. During endoscopic neck surgery, a $\mathrm{CO}_{2}$ injection pressure of $10 \mathrm{mmHg}$ or lower is considered safe, whereas a pressure of $15 \mathrm{mmHg}$ or above reportedly causes severe hypercapnia and acidosis [1]. Ochiai et al. [7] reported that the prevention of hypercarbia was achieved by using only $6 \mathrm{mmHg}$ of gas injection pressure during an endoscopic thyroidectomy, which was enough to secure an operative space.

During a laparoscopic/endoscopic surgery, it is difficult to predict the partial pressure of carbon dioxide in arterial blood $\left(\mathrm{PaCO}_{2}\right)$ with the $\mathrm{PetCO}_{2}$ because the alveolar-arterial oxygen gradient is not on the line when $\mathrm{PetCO}_{2}$ is higher [8]. Therefore, if the $\mathrm{PetCO}_{2}$ during a laparoscopic/endoscopic procedure is found to be higher, it is important to do arterial blood gas analyses frequently and use the information to measure the $\mathrm{PetCO}_{2}[9]$.

While trying to figure out the cause of the hypercapnia occurring during a laparoscopic/endoscopic surgery, clinicians must determine whether the condition is due to a meager increase in the amount of $\mathrm{CO}_{2}$ absorbed or is the result of other factors - such as hypoventilation resulting from respiratory obstruction or leakage in the respiratory cycle; abdominal inflation; posture of the patient; a ventilation-perfusion mismatch resulting from decreased cardiac output; and a host of other reasons including embolism, pneumothorax, subcutaneous emphysema, endotracheal intubation, and malignant hyperthermia [10].

Subcutaneous emphysema can be caused by the gathering of gas under the skin, which occurs during a laparoscopic/ endoscopic procedure, and can be detected by feeling the vibrations from the crepitant rales. The emphysema is accompanied by increased airway pressure and elevated levels of PetCO and these conditions could result in marked hypercapnia as well as respiratory acidosis. According to Sumpf et al. [5], an incident of subcutaneous emphysema during a laparoscopic extraperitoneal pelvic procedure resulted in the $\mathrm{CO}_{2}$ absorption three times the $\mathrm{CO}_{2}$ absorption observed during a similar procedure where subcutaneous emphysema did not occur. The researchers reported that they were not able to normalize the PetCO ${ }_{2}$, despite the marked increase in the respiratory minute ventilation. Their results imply that it is important for clinicians to suspect the occurrence of subcutaneous emphysema during a laparoscopic/endoscopic surgery if they observe continued hypercapnea during the procedure despite the typical increase in minute ventilation.

In the event of subcutaneous emphysema, the use of $\mathrm{N}_{2} \mathrm{O}$ must be discontinued, and the gas injection pressure be reduced. In the case of subcutaneous emphysema in the head and/or the neck, the pharynx should be observed directly by using a laryngoscope before removing the tube from inside the trachea. Direct observation is necessary since respiratory obstruction may result from emphysema in the pharynx [11].

Alveolar rupture and iatrogenic damages to the pleura or the diaphragm are among the causes of pneumothorax that is associated with anatomical damages occurring during laparoscopy. If a patient was suffering from lung bullae, that condition could lead to increased risks of alveolar rupture due to increases in respiratory minute ventilation that are intended to treat hypercapnia. Pneumothorax, which occurs without causing anatomical damages in patients, can result from either congenital defects found between the pleural and abdominal cavities; from the injected gas migrating into the thoracic area along with the retroperitoneal space; from gas leakage 
resulting from a high injection pressure; or from the migration of gas through the weakest site in the aortic or esophageal hiatus when the surgery takes a long time [12]. Subcutaneous emphysema spreading widely across the abdominal area could further spread to the thoracic wall and then to the neck, following the continuous planes of the fascia; subcutaneous emphysema in the neck and face may cause gas tracking in the thoracic area and mediastinum, possibly resulting in pneumothorax and mediastinal emphysema [3]. In our case report, postoperative CT scans showed no abnormalities in the patient's lungs; no noteworthy events occurred either during the surgery, which might lead to iatrogenic damages; however, severe subcutaneous emphysema was found in the neck, shoulders, and thoracic wall. Based on these findings, we suspect the patient's pneumothorax was caused by gas tracking resulting from subcutaneous emphysema. Thus, we recommend mandatory postoperative chest X-rays for patients with subcutaneous emphysema in the neck, though perhaps asymptomatic, to exclude the possibilities of pneumothorax and mediastinal emphysema [10].

Symptoms of pneumothorax vary widely from no symptoms to cardiac arrest, depending on the size of the pneumothorax and its development speed, which affects the patient's cardiovascular system, as well as on the patient's cardiopulmonary functioning. The symptoms may also include increased PIP, decreased pulmonary compliance, increased $\mathrm{PetCO}_{2}$, decreased oxygen saturation, and hypotension [12].

To treat pneumothorax during a laparoscopy, clinicians need to stop the infusion of $\mathrm{CO}_{2}$ or reduce the injection pressure, discontinue the use of $\mathrm{N}_{2} \mathrm{O}$, increase hyperventilation and the fraction of inspired oxygen, and maintain hemodynamic stability when necessary. Pleural puncture may not be needed unless to treat unstable respiration or the hemodynamic condition of the patient since $\mathrm{CO}_{2}$ is easily absorbed in the body [13]. Joris et al. [14] reported they treated pneumothorax during a laparoscopic Nissen fundoplication by applying $\mathrm{PetCO}_{2}$ without performing thoracentesis. They argued that the treatment worked because $\mathrm{PetCO}_{2}$ helped reduce the difference in pressure between the abdominal and thoracic cavities, expanded the contracted lungs, and prevented mechanically the defects in the visceral pleura.

Hypercapnia, subcutaneous emphysema, pneumothorax, and mediastinal emphysema encountered during laparoscopy are reportedly the result of a long surgery lasting more than 200 minutes or high $\mathrm{PetCO}_{2}$ levels ( $50 \mathrm{mmHg}$ or above), and their likelihood reportedly increases with a growing number of trocars used during the surgery and with a patient with advanced age [15]. However, clinicians must remember that complications can occur anytime, as in our case where there were not many risk factors to trigger the complications.
In conclusion, clinicians are advised to suspect subcutaneous emphysema during endoscopic thyroidectomy when hypercapnia is not corrected with an increase in the respiratory minute ventilation, which is a standard approach in dealing with hypercapnia, as well as the resulting possibility of pneumothorax. Clinicians are also advised to consider the possibilities of intraoperative hemodynamic and respiratory complications. When suspecting such complications, clinicians must closely monitor the patient's PetCO ${ }_{2}$, oxygen saturation, PIP, and pulmonary compliance. Close consultation with the surgeon is also required to take into account the inspired gas pressure, duration of the surgery, and other related factors.

\section{References}

1. Bellantone R, Lombardi CP, Rubino F, Perilli V, Sollazzi L, Mastroianni $\mathrm{G}$, et al. Arterial $\mathrm{PCO}_{2}$ and cardiovascular function during endoscopic neck surgery with carbon dioxide insufflation. Arch Surg 2001; 136: 822-7.

2. Menes T, Spivak H. Laparoscopy: searching for the proper insufflation gas. Surg Endosc 2000; 14: 1050-6.

3. Gerges FJ, Kanazi GE, Jabbour-khoury SI. Anesthesia for laparoscopy: a review. J Clin Anesth 2006; 18: 67-78.

4. Kim SH, Park KS, Shin HY, Yi JH, Kim DK. Paradoxical carbon dioxide embolism during endoscopic thyroidectomy confirmed by transesophageal echocardiography. J Anesth 2010; 24: 774-7.

5. Sumpf E, Crozier TA, Ahrens D, Brauer A, Neufang T, Braun U. Carbon dioxide absorption during extraperitoneal and transperitoneal endoscopic hernioplasty. Anesth Analg 2000; 91: 589-95.

6. Mullet GE, Viale JP, Sagnard PE, Miellet CC, Ruynat LG, Counioux $\mathrm{HC}$, et al. Pulmonary $\mathrm{CO}_{2}$ elimination during surgical proceures using intra-or extraperitoneal $\mathrm{CO}_{2}$ insufflation. Anesth Analg 1993; 76: 622-6.

7. Ochiai R, Takeda J, Noguchi J, Ohgami M, Ishii S. Subcutaneous carbon dioxide insufflation does not hypercarbia during endoscopic thyroidectomy. Anesth Analg 2000; 90: 760-2.

8. Kent RB 3rd. Subcutaneous emphysema and hypercarbia following laparoscopic cholecystectomy. Arch Surg 1991; 126: 1154-6.

9. Gottlieb A, Sprung J, Zheng XM, Gagner M. Massive subcutaneous emphysema and severe hypercarbia in a patient during endoscopic transcervical parathyroidectomy using carbon dioxide insufflation. Anesth Analg 1997; 84: 1154-6.

10. Joshi GP. Complications of laparoscopy. Anesthesiol Clin North America 2001; 19: 89-105.

11. Kim HY, Kim TY, Lee KC, Lee MJ, Kim SH, Bahn JM, et al. Peumothorax during laparoscopic totally extraperitoneal inguinal hernia repair -A case report-. Korean J Anesthesiol 2010; 58: 490-4.

12. Cha SM, Jung YH, Kim DS, Kang H, Baek CW, Koo GH. Spontaneous pneumothorax during laparoscopy-assisted Billorth-I gastroscopy. Korean J Anesthesiol 2010; 58: 405-8.

13. Harkin CP, Sommerhaug EW, Mayer KL. An unexpected complication during laparoscopic herniorrhaphy. Anesth Analg 1999; 89: 1576-8.

14. Joris JL, Chiche JD, Lamy ML. Pneumothorax during laparoscopic 
fundoplication: diagnosis and treatment with positive endexpiratory pressure. Anesth Analg 1995; 81: 993-1000.

15. Murdock CM, Wolff AJ, Van Geem T. Risk factors for hypercarbia, subcutaneous emphysema, pneumothorax, and pneumomediastinum during laparoscopy. Obstet Gynecol 2000; 95: 704-9. 